\title{
EL DESPIDO OBJETIVO O COLECTIVO DE TRABAJADORES ESPECIALMENTE SENSIBLES
}

STJUE 11.9.2019 (ASUNTO C-397/18, NOBEL PLASTIQUES)

Francisco Ramón Lacomba Pérez

Abogado del Área de Gestión de Conocimiento de Cuatrecasas

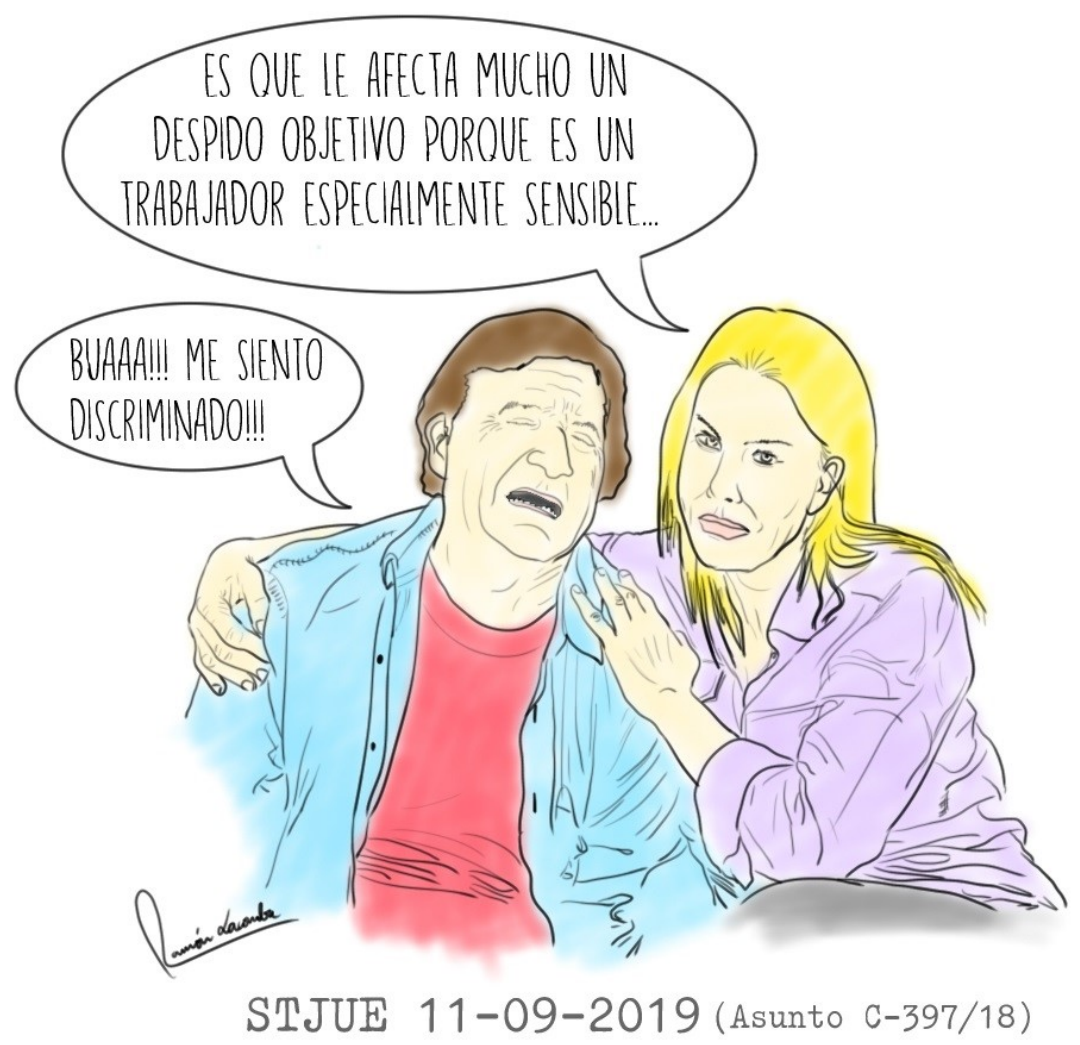

Title: Objective or collective dismissal of specially sensitive workers

Palabras clave: despido objetivo, despido colectivo, trabajadores especialmente sensibles, ajustes razonables.

Keyworrds: objective dismissal, collective dismissal, specially sensitive workers, reasonable adjustments

IUSLabor 3/2019, ISSN 1699-2938, p. 152-155

DOI. 10.31009/IUSLabor.2019.i03.06

Fecha envío: 8.11.2019 | Fecha aceptación: 15.11.2019 
La Sentencia del TJUE de 11 de septiembre de 2019 (Asunto C-397/18), Caso Nobel Plàstiques Ibèrica, objeto del presente comentario, advierte acerca del riesgo de discriminación indirecta por razón de discapacidad que puede conllevar la afectación en despidos objetivos o colectivos de trabajadores identificados a efectos preventivos como "especialmente sensibles" (TES) ${ }^{1}$, aunque igualmente apunta cómo neutralizar dicho riesgo.

Vienen siendo criterios de selección potencialmente razonables y objetivos, generalmente aceptados, referencias tales como el nivel de productividad del trabajador $^{2}$, su grado de polivalencia en los puestos de trabajo de la empresa o su índice de absentismo ${ }^{3}$. Sin embargo, la Sentencia que ahora referenciamos llama la atención sobre el hecho de que, cuando se plantea la aplicación de tales criterios de selección a trabajadores especialmente sensibles, dichos criterios pueden resultar indirectamente discriminatorios por razón de discapacidad.

En el supuesto enjuiciado, la empresa acordó en el período de consultas la aplicación de este tipo de criterios de designación, que utilizó para afectar a una trabajadora que años atrás había sido diagnosticada de una epicondilitis, calificada de enfermedad profesional. Debido a esta dolencia, en la trabajadora concurrían las siguientes circunstancias:

- Tenía reconocida la condición de "trabajadora especialmente sensible a los riesgos derivados del trabajo", en el sentido del artículo 25 Ley 31/1995, situación en la que seguía desde entonces

\footnotetext{
${ }^{1}$ El artículo 25.1 Ley 31/1995, de 8 de noviembre, de prevención de Riesgos Laborales (LPRL) define a estos trabajadores como aquellos que, "por sus propias características personales o estado biológico conocido, incluidos aquellos que tengan reconocida la situación de discapacidad fisica, psíquica o sensorial, sean especialmente sensibles a los riesgos derivados del trabajo".

${ }^{2}$ Por ejemplo, la SAN (Social) de 11-03-2013 (proc. 381/2012) considera los criterios de selección basados en las fichas personales de todos los trabajadores (ya utilizadas previamente en la compañía) y en una evaluación del desempeño basada en el rendimiento, como "un medidor razonable y objetivo, que se cohonesta plenamente con el objetivo propuesto: mejorar la competitividad y productividad de la empresa" y que además "permite mantener en la plantilla a los trabajadores más productivos, lo que constituye un bien en sí mismo para una empresa".

${ }^{3}$ Por citar una entre otras muchas, la STSJ Castilla-La Mancha 10-04-2017 (Rec. 86/2017), por ejemplo, valida la designación de los trabajadores afectados por el despido colectivo con base en una evaluación multifactorial (formación, experiencia, polivalencia, implicación, absentismo, puntualidad, etc) que estima suficientemente explicativa de los criterios a seguir (que señala como objetivamente valorables) y considera respetuosa con los derechos fundamentales y ordinarios de los trabajadores, al tiempo que no fueron cuestionados durante la negociación.
} 
- Había acudido en diversas ocasiones al servicio médico de la empresa quejándose de dolor en el codo y había remitido diversas comunicaciones al servicio médico y a la empresa reclamando la adecuación de su puesto de trabajo a su situación física, adecuación que no se había acometido suficientemente

- Había pasado por diversos períodos de incapacidad temporal derivada de accidente de trabajo, sometiéndose a un reconocimiento médico después de cada alta médica, que concluían con una calificación de la trabajadora como "apta con limitaciones".

Con estos antecedentes, no era difícil que la trabajadora cumpliese los criterios de selección pactados: presentaba una productividad media menor que otros trabajadores; una polivalencia muy reducida en las tareas fundamentales de su puesto de trabajo; y un índice de absentismo del 69,55\%. Por todo ello, la trabajadora fue afectada en el despido colectivo llevado a cabo.

La trabajadora impugnó su despido recurriendo el argumento principal de que la medida suponía una discriminación indirecta por razón de discapacidad, razonamiento con el que llega al TJUE.

No es una problemática nueva. Ya nos había advertido la Sala de lo Social de la Audiencia Nacional acerca del cuidado que debe observarse en la aplicación de criterios de designación como el absentismo. Por ejemplo, la SAN (Social) 11-112014 (proc. 251/2014) consideró que emplear como criterio de selección el absentismo de larga duración no es discriminatorio, porque no es la causa del despido, sino un mero criterio de selección (fuera del supuesto de hecho del artículo 52.d. ET). Pero nos avisó la Sala que dicho criterio puede resultar discriminatorio cuando afecte a trabajadores que sufran enfermedades de naturaleza estigmatizante o cuando afecte a trabajadores cuya situación pueda calificarse de discapacidad, aunque no sea definitiva, en los términos de la jurisprudencia del TJUE. En cualquier caso, -matizó- no sería una causa de nulidad del despido colectivo en su conjunto, sino una cuestión a valorar en los litigios individuales.

En línea con esta advertencia, se pronuncia ahora el TJUE, en esta Sentencia que analizamos, cuyo mensaje principal es que la afectación de un trabajador reconocido como especialmente sensible en un despido objetivo o colectivo puede conllevar un grave riesgo de discriminación indirecta por motivos de discapacidad, en el sentido del artículo 2.2.b.ii) de la Directiva 2000/78. Según la Sala, así habrá de declararse si se concluye que estamos ante una persona considerada con "discapacidad", en el sentido de la Directiva 2000/78, es decir, no necesariamente con un reconocimiento 
oficial de su discapacidad, sino simplemente aquejada de una dolencia que implique una limitación de la capacidad "a largo plazo", esto es, duradera, porque médicamente o no se sepa si curará pronto o se sepa que tardará mucho en curar, y que le impida la participación plena y efectiva en la vida profesional en igualdad de condiciones con los demás trabajadores ${ }^{4}$.

Ahora bien, nos indica la Sala también cómo neutralizar el señalado riesgo de discriminación indirecta. En concreto, podría la empresa reducir o eliminar esa potencial discriminación si ha realizado previamente adaptaciones "suficientes" en su puesto de trabajo, pero no sólo como medida de prevención del artículo 25 Ley 31/1995), sino también para eliminar las posibles barreras que le impidan desarrollar sus funciones en igualdad de condiciones que el resto de trabajadores (tal y como exigen los artículos 5 Directiva y 40 Real Decreto Legislativo 1/2013), de tal manera que permita objetivamente al TES alcanzar índices de productividad, polivalencia y absentismo comparables con los del resto de la plantilla potencialmente afectada por la medida extintiva.

Sin duda, se trata de un pronunciamiento relevante que, aunque excluye la automaticidad de la discriminación por discapacidad en estos supuestos, previene sobre la existencia de este riesgo y la conveniencia de integrar a los trabajadores especialmente sensibles en el mismo nivel de productividad que el resto de la plantilla, mediante las adaptaciones que se requieran en sus puestos y condiciones de trabajo.

\footnotetext{
${ }^{4}$ Es indispensable que la situación de salud del trabajador sea equiparable, en los términos indicados, a una situación de discapacidad, ya que, si no es el caso, quedaría abortado el riesgo de discriminación indirecta por esta vía. Así se entendió, por ejemplo, en la STS 20-05-2015 (Rec. 290/2014), en la que el Tribunal rechaza la existencia de indicios de discriminación en relación con criterio de selección que otorga prioridad a los trabajadores en activo frente a los que están en situación de incapacidad temporal, ello al considerar que la sentencia del TJUE (Asunto RING) pivota sobre un concepto mucho más complejo de discapacidad y no se refiere a un supuesto de incapacidad temporal para el trabajo en abstracto, por lo que no sería de aplicación a este supuesto. Además, el TS recuerda que las situaciones de excedencia o incapacidad temporal sin más no se encuentran listadas entre las causas de discriminación recogidas en el artículo 17.1 ET. En concreto, desestima el motivo porque no se ha acreditado que los trabajadores excedentes fueran mujeres ni que pidieran la excedencia para el cuidado de sus hijos.
} 